\title{
PROJETO ARQUITETÔNICO DE CENTRO COMERCIAL E DE SERVIICOOS: CONCEITOS E CONCEPÇÃO DE UM EDIFÍCIO ABERTO À CIDADE
}

\author{
RAMOS, HENRIQUE S. M. \\ Arquiteto, MsC; email: henriquesmramos@gmail.com \\ Dissertação desenvolvida no Mestrado Profissional em Arquitetura, Projeto e Meio Ambiente da UFRN \\ Orientadora: Profa. Edja B. F Trigueiro, PhD; Co-orientadora: Profa Dra Maísa F. Dutra Veloso
}

\section{RESUMO EXPANDIDO}

Este texto apresenta a definição de conceitos e o processo de concepção de um edifício comercial e de serviços, cuja configuração favorece sua relação com o espaço público. O projeto, integrante de dissertação defendida junto ao curso de Mestrado Profissional em Arquitetura, Projeto e Meio Ambiente da UFRN no ano de 2016, foi proposto para um terreno localizado no bairro de Lagoa Nova, Natal-RN.

A noção de que os espaços de edifícios comerciais promovem a desconexão entre os âmbitos público e privado nas cidades justificou um dos objetivos da pesquisa, uma vez que essa desconexão impacta negativamente nas atividades econômicas nestes locais, além de contribuir para o esvaziamento dos espaços urbanos. Apesar da recente produção de edifícios cada vez mais herméticos ao espaço da cidade, estudos de morfologia e usos da arquitetura ensejam que outra realidade é possível, na qual a forma e a configuração do ambiente construído contribuem para geração de lugares com maior potencial para o movimento e a permanência de pessoas (HOLANDA, 2010; GARCIA et al, 2011; TENÓRIO, 2012; NETTO, VARGAS e SABOYA, 2012). Com base na teoria da sintaxe espacial, que usa relações matemáticas e ferramentas computacionais para descrever e compreender espaço e forma urbanos e suas implicações sociais, defende-se que a forma edilícia tem efeitos sobre o desempenho do edifício como elemento indutor de vitalidade urbana, copresença, e urbanidade.

O processo de concepção projetual foi então estruturado a partir da identificação de tais atributos para o edifício pretendido, sendo vitalidade urbana materializada por continuidade edilícia, diversidade de usos, conexão entre os âmbitos público e privado, densidade satisfatória e configuração da malha que favoreça movimento e presença de pessoas (NETTO, VARGAS e SABOYA, 2012; VARGAS, 2003; HILLIER et al, 1993; JACOBS, 2014 [1961]); copresença encontrada em espaços que favorecem a percepção da existência do outro - cociência, e da coexistência dos corpos em um mesmo lugar, possibilitando tanto interações espontâneas entre seus múltiplos atores, ou apenas os "contatos passivos de se ver e ouvir" a que se refere Jan Ghel (HOLANDA, 2013; JACOBS, 2014 [1961]; GEHL, 2013); e urbanidade representada por espaços urbanos com forte presença e diversidade de pessoas e atividades, ênfase na escala humana, nas relações de pertencimento com o lugar e em sensações de conforto e segurança (HOLANDA, 2002, 2010 e 2011; TENÓRIO, 2012; NETTO, 2014).

Apoiada em tais embasamentos teórico-conceituais, a proposta arquitetônica para um edifício de uso comercial e de serviços foi desenvolvida, procurando maximizar a relação entre os espaços público e privado. Quanto aos procedimentos metodológicos empregados, após a revisão bibliográfica para definição do referencial teórico a ser adotado como condutor do partido arquitetônico, assim como a revisão de experiências projetuais que enfatizam urbanidade, vitalidade urbana e copresença, foram também realizados: pesquisa de referenciais de projeto com temáticas similares ao edifício proposto, por meio de análise configuracional com ferramentas da teoria da sintaxe espacial; análises tipológica e programática de edifícios construídos, cujos programas arquitetônicos eram pertinentes ao projeto a ser elaborado; e desenvolvimento da proposta arquitetônica, desde a definição do terreno e análise dos condicionantes do projeto, passando pela elaboração de conceitos e de um partido arquitetônico, chegando até o nível de anteprojeto de arquitetura. 
Para o desenvolvimento da proposta, identificaram-se atividades inseridas em cada uma das três classificações do processo de projeto apresentadas por Lawson (2011) e detalhadas por Andrade, Ruschel e Moreira (2011), referidas por esses autores por análise, síntese e avaliação. O quadro 1 relaciona as atividades específicas ao processo de elaboração projetual da proposta.

Quadro 1 - Resumo das atividades do processo de elaboração da proposta arquitetônica

\begin{tabular}{|c|c|c|}
\hline Análise & Síntese & Avaliação \\
\hline Conformação do terreno & \multirow[t]{2}{*}{ Diagramas } & \multirow[t]{2}{*}{ Comparação com metas } \\
\hline Aspectos normativos & & \\
\hline Observação do entorno & \multirow[t]{2}{*}{ Esquemas / Croquis } & \multirow{4}{*}{$\begin{array}{l}\text { Comparação c/ programa de } \\
\text { necessidades }\end{array}$} \\
\hline Análises configuracionais & & \\
\hline Aspectos climáticos & \multirow[t]{2}{*}{ Detalhamentos } & \\
\hline Estudos tipológicos & & \\
\hline $\begin{array}{l}\text { Identificação de conceitos na } \\
\text { literatura }\end{array}$ & \multirow[t]{2}{*}{ Plantas } & \multirow[t]{2}{*}{$\begin{array}{l}\text { Comparação com referenciais } \\
\text { empíricos }\end{array}$} \\
\hline Referenciais empíricos & & \\
\hline Visitas técnicas & \multirow[t]{2}{*}{ Elevações } & \multirow{2}{*}{$\begin{array}{l}\text { Simulações de parâmetros de } \\
\text { Conforto }\end{array}$} \\
\hline Definição de metas & & \\
\hline Pré-dimensionamento & \multirow[t]{2}{*}{ Modelo Tridimensional } & \multirow{2}{*}{$\begin{array}{l}\text { Simulações de Sintaxe do } \\
\text { espaço }\end{array}$} \\
\hline Programa arquitetônico & & \\
\hline
\end{tabular}

Fonte: O autor, 2016

Um diagrama-síntese foi elaborado para melhor ilustrar graficamente o significado que se pretendia atribuir à forma arquitetônica, em atendimento a algumas palavras chaves, que também teriam rebatimento na proposta. Ao final, foram definidos Movimento e Encontro como conceitos para o projeto (ver Quadro 2). São estas as características desejadas para a viabilidade do empreendimento e conformação dos atributos de vitalidade urbana, copresença e urbanidade. Conciliar tais atributos com aspectos essenciais, como estratégias bioclimáticas e de segurança, complementaram a visão para sua arquitetura.

Quadro 2 - Palavras-chaves, diagrama-síntese e conceitos a serem rebatidos na proposta projetual

\begin{tabular}{|c|c|c|}
\hline Palavras-chaves & Diagrama-Síntese & Conceitos \\
\hline $\begin{array}{c}\text { Visibilidade } \\
\text { Animação } \\
\text { Copresença } \\
\begin{array}{c}\text { Acessibilidade } \\
\text { Diversidade }\end{array}\end{array}$ & $\begin{array}{c}\text { Movimento } \\
\text { Encontro }\end{array}$ \\
\hline
\end{tabular}

${ }^{1}$ Acessibilidade aqui se refere à qualidade do espaço de ser acessível a partir de diferentes pontos do sistema urbano. 
A definição do terreno para desenvolvimento do projeto foi auxiliada por análises de sintaxe espacial (mapas axial e de segmento) e por observações in loco, com o intuito de verificar a existência de potencial de movimento (ver Figura 1). O terreno escolhido encontra-se inserido no núcleo integrador de Natal e conta com 3.602,83 $\mathrm{m}^{2}$ de superfície, com testadas voltadas para três vias (sendo duas Avenidas e uma rua local) e extensos perímetros de fachada, favorecendo a instalação de lojas com relação visual direta com as vias do entorno.

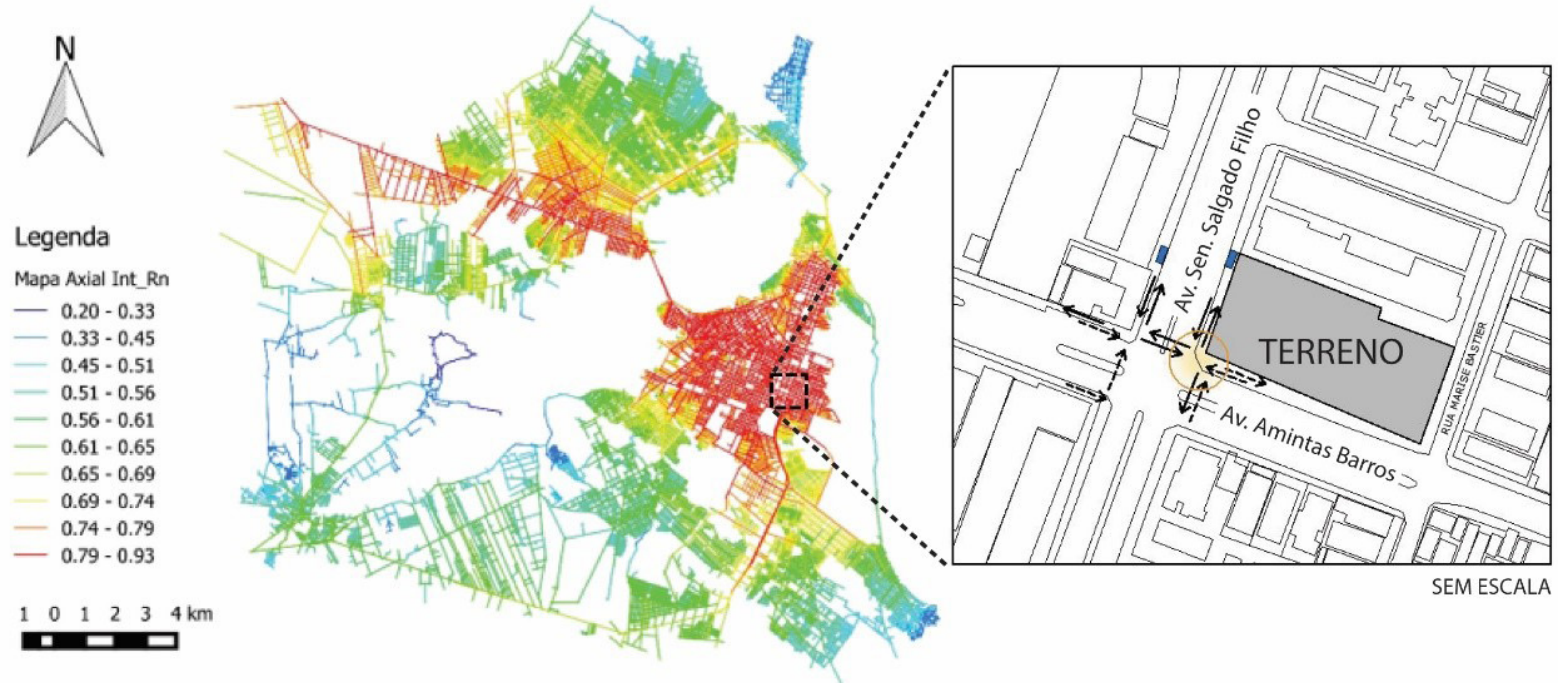

Fonte: DONEGAN, 2014 (tratado pelo autor)

O estudo preliminar foi desenvolvido a partir do entendimento do processo criativo como atividade não linear (Lawson, 2011), priorizando distintas soluções de implantação, de volumetrias das partes e de design de elementos de sombreamento que permitissem responder às demandas identificadas na fase de análise do processo de projeto.

O partido adotado contempla pavilhões de lojas ao longo das fachadas das avenidas principais de acesso ao local e um edifício de escritórios organizados em prismas horizontais sobre o terreno, abrigando 20 lojas para diferentes usos e 54 salas comerciais do programa arquitetônico. No nível térreo, abre-se uma extensa praça, conectada física e visualmente aos espaços públicos, sendo os estacionamentos distribuídos em dois níveis de subsolo. No pavimento de cobertura, um terraço panorâmico inclui uma sala multiuso e espaços de convivência para o empreendimento.

Figura 2 - Croquis e maquete volumétrica digital elaborados na fase de estudo preliminar

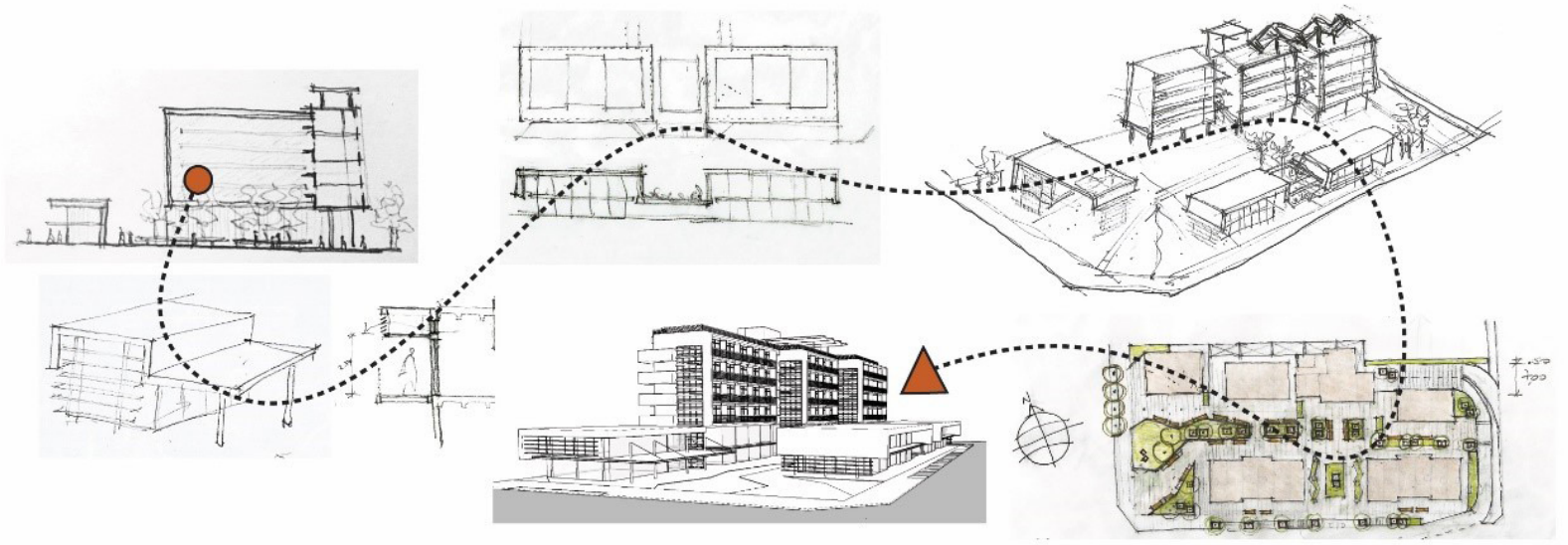


Utilizando-se o programa Depthmap como ferramenta de sintaxe espacial para avaliação da proposta, simulações de análise de grafos visuais e de isovistas foram realizadas, desde a fase de estudo preliminar e no desenvolvimento da proposta em nível de anteprojeto, para registro das propriedades espaciais alcançadas pela configuração final do pavimento térreo (ver Figuras 3 e 4). Estas análises permitiram concluir que a configuração proposta potencializa a integração visual do espaço interno do centro comercial com o entorno urbano imediato, e entre diversos pontos dentro dos limites do espaço, relacionados entre si. Esta verificação confirma o atendimento da proposta à premissa mais importante colocada para este projeto: potencializar a ocorrência de movimento e encontro para passantes e usuários do empreendimento.

Figura 3 - Análises de Grafo Visual para o pavimento térreo da proposta para o Centro Comercial

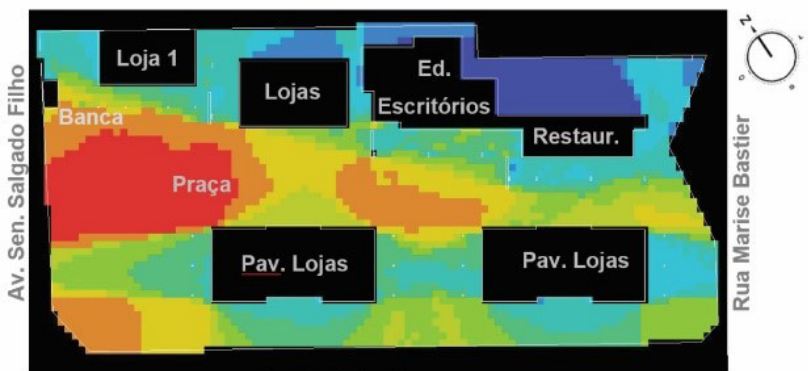

Av. Amintas Barros

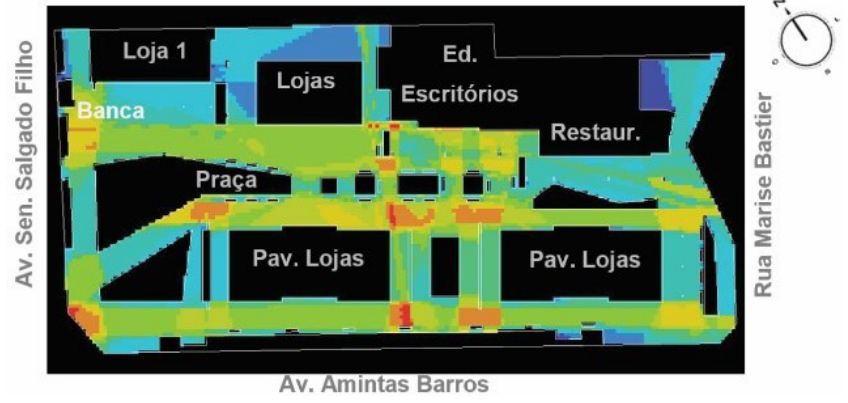

Av, Amintas Barros

Fonte: $O$ autor, 2016

Figura 4 - Isovistas geradas em diferentes pontos do térreo para a proposta do Centro Comercial
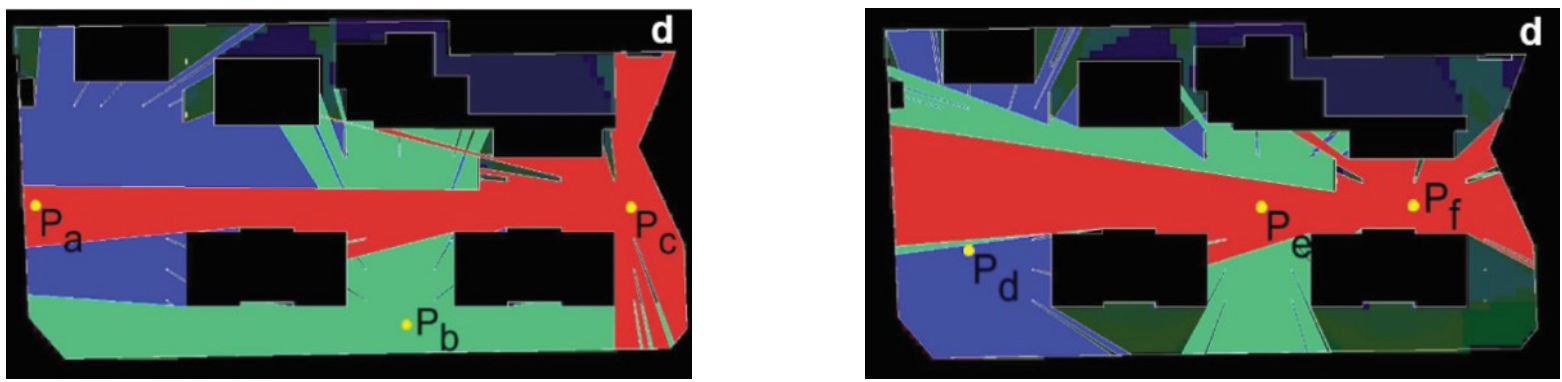

Fonte: $O$ autor, 2016

A volumetria adotada se baseou na separação e legibilidade dos volumes que compõem o programa arquitetônico, sendo a maioria das lojas dispostas em dois pavilhões e as salas comerciais em um edifício com 6 pavimentos elevados sobre pilotis. Nos pavimentos elevados, tem-se um mezanino, quatro pavimentostipo e um pavimento de cobertura. Os dois pavilhões de lojas apresentam, por sua vez, dois níveis - térreo e mezanino. 
Figura 5 - Plantas e elevações do anteprojeto de arquitetura para o Centro Comercial

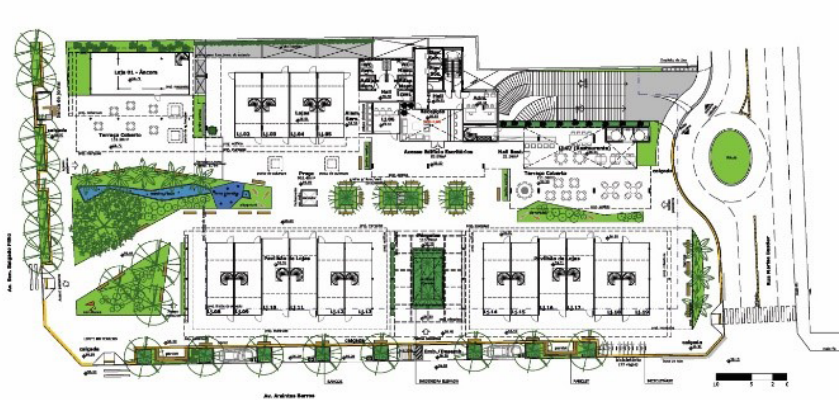

PL. PAVIMENTO TÉRREO

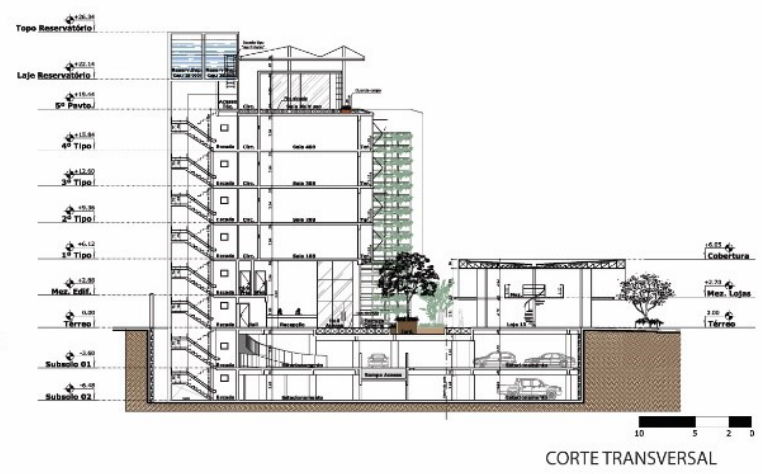

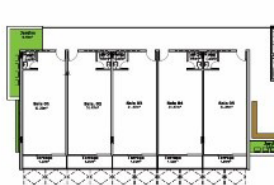

Dados do Projeto Gabarito $=26,34 \mathrm{~m}$

No. Vagas Estac. $=155$

Área Construída $=9.672,30 \mathrm{~m}^{2}$
Area

Área Computável $=5.261,42 \mathrm{~m}^{2}$

Coef. Aproveitamento $=1.46$

TX. Ocupação $=55,28 \%$ (térreo)

Tx. Ocupação $=55,28 \%$ (térreo)
Tx. Permeabilidade $=21,48 \%$
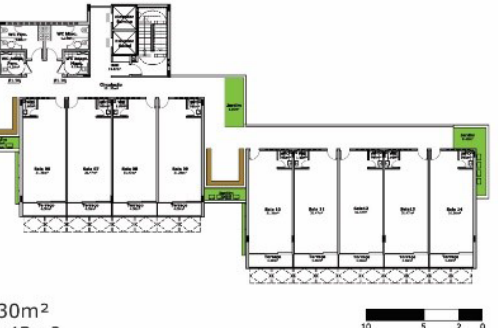

PL. PAVIMENTOTIPO

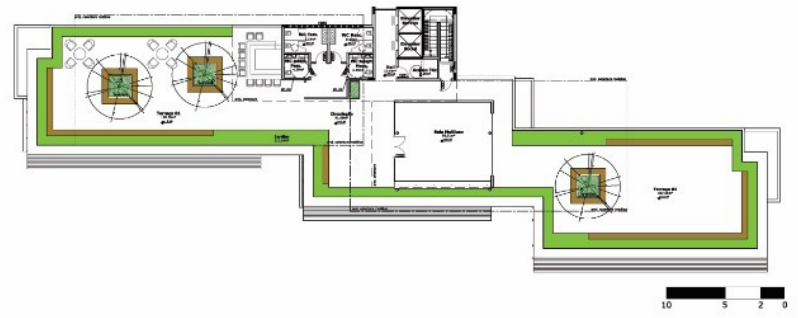

PL. PAVIMENTO COBERTURA

Fonte: O autor, 2016

A proposta tem a praça como articuladora dos edifícios do programa, bem como a liberação do solo no nível do térreo. Sendo movimento e encontro os conceitos adotados, além da ênfase da liberação da praça para gerar a espacialidade propícia a tais atividades, a composição volumétrica também se apropria da ideia de movimentação dos prismas sobre o solo, da diversidade de alturas entre blocos, dos desalinhamentos entre prismas, da sinuosidade do elemento de cobertura e de permeabilidade visual entre os espaços internos e externos, de forma a expressar materialmente, na arquitetura, as ideias originárias na resposta projetual

Figura 6 - Perspectivas do Centro Comercial, a partir da Av. Sen. Salgado Filho
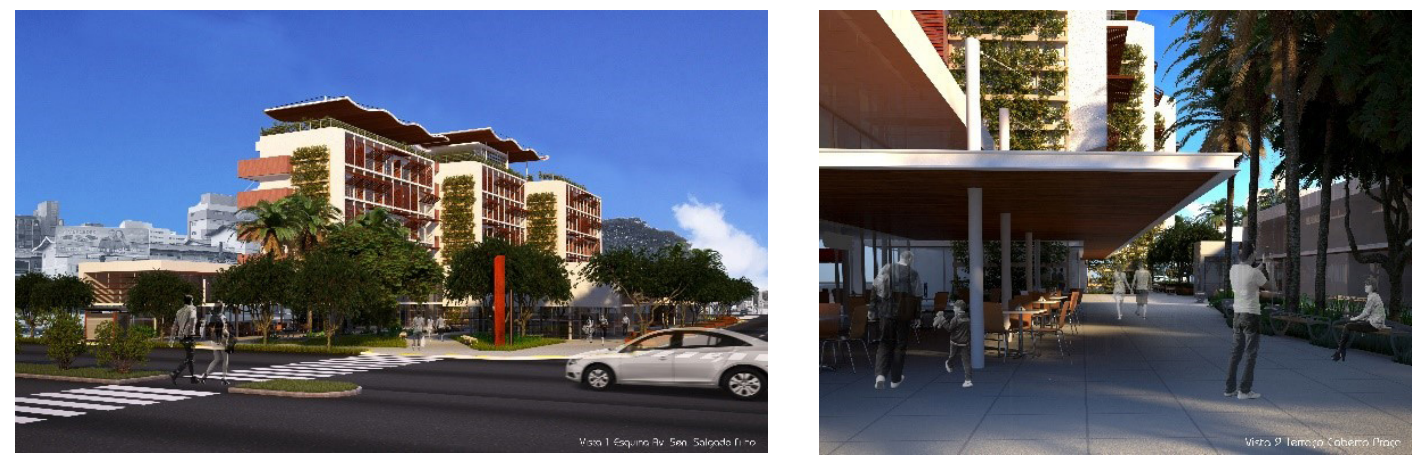

Fonte: O autor, 2016

Figura 7 - Perspectivas do Centro Comercial, a partir da praça central e da Av. Amintas Barros
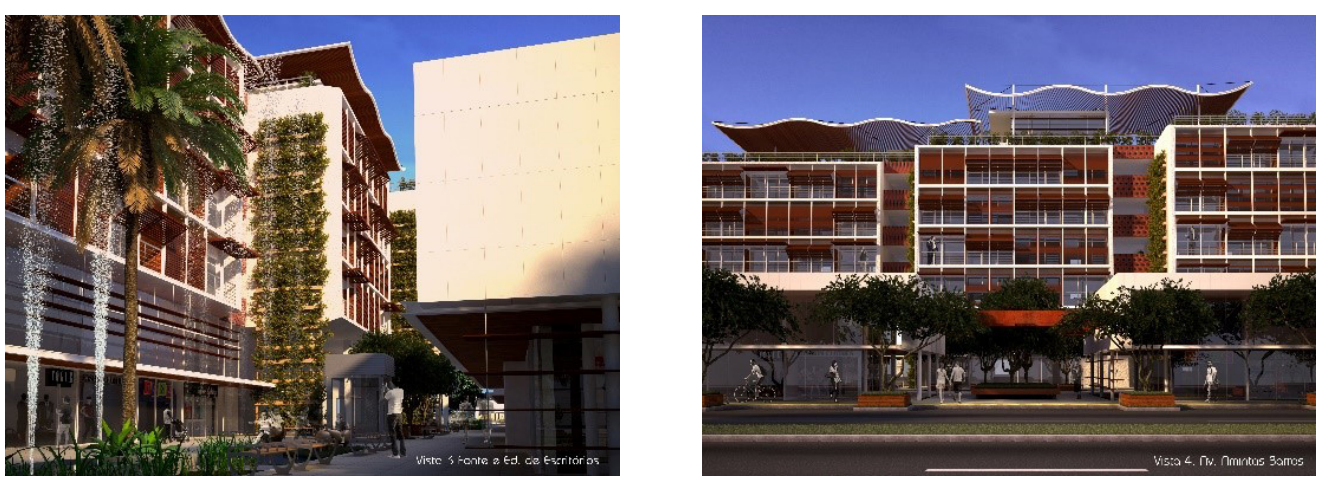

Fonte: O autor, 2016 
Os resultados obtidos demonstraram que é possível conceber, com o devido respaldo teórico e científico, um projeto arquitetônico de um empreendimento privado de uso público de forma distinta à tendência em geral disseminada pelo mercado imobiliário, ao mesmo tempo em que contempla demandas tanto do setor varejista, quanto dos usuários, em atenção ao contexto de nossas cidades. Defende-se, assim, que deve ser permitido ao arquiteto e urbanista, explorar uma configuração e atributos de uma urbanidade perdida em algum lugar de nossas memórias de como as cidades e seus edifícios deveriam funcionar, favorecendo a vitalidade e a copresença no âmbito público. Movimento e encontro devem ser priorizados, para que as pessoas possam usufruir do melhor das cidades e de seus edifícios.

\section{REFERÊNCIAS}

ANDRADE, Max L. X. de; RUSCHEL, Regina Coeli; MOREIRA, Daniel de Carvalho. O processo e os métodos. In: KOWALTOWSKI, Doris C. C. K. et al. (Org.). Processo de projeto em arquitetura: da teoria à tecnologia. São Paulo: Oficina do Texto, 2011. Cap. 4. p. 80-100.

DONEGAN, Lucy. Mapa axial de Natal, Natal: UFRN, 2014.

GARCIA, Cláudia da Conceição et al. Passado, presente e futuro de uma avenida moderna: W-3, Brasília. In: HOLANDA, Frederico de (Org). Arquitetura e Urbanidade. 2.ed. Brasília: FRBH, 2011. p. 66-93.

GEHL, Jan. Cidades para pessoas. 2. ed. São Paulo: Perspectiva, 2013. 262 p.

HILLIER, Bill et al. Natural movement: or, configuration and attraction in urban pedestrian movement. Environment and Planning B: Planning and Design, v. 20, n. 1, p. 29-66, 1993.

HOLANDA, Frederico de. O espaço de exceção. Brasília: Editora UnB, 2002. 466 p.

HOLANDA, Frederico de (Org.). Arquitetura e Urbanidade. 2.ed. Brasília: FRBH, 2011. p.13-16.

HOLANDA, Frederico de. 10 mandamentos da arquitetura. Brasília: FRBH, 2013. 341 p.

JACOBS, Jane. Morte e vida de grandes cidades. 3.ed. São Paulo: Wmf Martins Fontes, 2014[1961]. 510p.

LAWSON, Bryan. Como arquitetos e designers pensam. São Paulo: Oficina de Textos, 2011.

NETTO, Vinicius M.; VARGAS, Júlio César; SABOYA, Renato T. de. (Buscando) Os efeitos sociais da morfologia arquitetônica. Urbe. Revista Brasileira de Gestão Urbana, Curitiba, v.4, n.2, p.261-282, jul./dez. 2012.

NETTO, Vinícius M. Urbanidade e a condição do outro. In: Cidade \& sociedade: as tramas da prática e seus espaços. Porto Alegre: Sulina, 2014. p. 189-225.

RAMOS, Henrique S. M. Centro Comercial Avenida: um espaço aberto à cidade. Dissertação de Mestrado apresentada ao Programa de PósGraduação em Arquitetura e Urbanismo / Mestrado Profissional em Arquitetura, Projeto e Meio Ambiente. Natal, 2016.

TENORIO, Gabriela de Souza. Ao desocupado em cima da ponte: Brasília, arquitetura e vida pública. 2012. $391 f$. Tese (Doutorado em Arquitetura e Urbanismo)- Universidade de Brasília. Brasília, 2012. Disponível em: <http://repositorio.unb.br>. Acessado em: 26 out. 2014.

VARGAS, Júlio Celso Borello. Centros urbanos vitais: Configuração, dinâmica funcional e caráter das ruas comerciais de Porto Alegre. 2003. 222 f. Dissertação (Mestrado) - PROPUR, Universidade Federal do Rio Grande do Sul, Porto Alegre, 2003. Disponível em: <http://www. lume.ufrgs.br/>. Acessado em: 20 out. 2014.

NOTA DO EDITOR (*) O conteúdo do artigo e as imagens nele publicadas são de responsabilidade do(s) autor(es). 